\title{
Loss Performance Evaluation of Ferrite-Cored Wireless Power System with Conductive and Magnetic Shields
}

\author{
Babatunde Olukotun \\ J.S. Partridge \\ Mechanical Engineering Department \\ University College London \\ London, United Kingdom
}

\author{
Richard W.G. Bucknall \\ Mechanical Engineering Department \\ University College London \\ London, United Kingdom
}

\begin{abstract}
This paper presents a loss evaluation of ferrite-cored wireless power transfer (WPT) systems using conductive and magnetic shield materials. The modelling and analyses of the coil systems were implemented using the finite element method. Three coil systems were modelled- circular coils, rectangular coils and flux-pipe coil system using magnetic shields (Mumetal and electrical steel) and conductive shields (aluminium and copper). From the results presented in the analyses, it was noted that ohmic losses and core losses in the WPT system are independent of the type of conductive shield used. Similarly, it was noted that the self-inductance, coupling coefficient and losses in the system is affected by the type of magnetic shield used. For the flux-pipe resonant coil system, high amount of power losses was recorded when a magnetic shield was used as the shielding topology while low amount of power losses was recorded in the circular coil and rectangular coil resonant systems when the magnetic shield was used as the shielding material.

For an optimal WPT system requiring a low amount of eddy current losses, it was established that copper shield is the appropriate choice for flux-pipe resonant coils while electrical steel is the suitable shield material for the circular resonant coil and rectangular resonant coil systems.
\end{abstract}

Keywords - Finite element analysis, conductive shield, magnetic shield, coupling coefficient, self-inductance, ohmic losses, core losses, eddy current losses.

\section{INTRODUCTION}

Ferrite-core magnetic resonant coupling WPT technology is the most commonly used technology used for the charging of electric vehicle because of the capability of transferring high power at high efficiency at a relatively low cost[1]. Many different WPT models have been proposed by many researchers. The common models deployed for practical charging of electric vehicles are the flux-pipe coils, rectangular coils and circular coils[2]-[4]. Common ferrite cored coil geometric designs are shown in Figure 1.

The optimal coil designs need to take into consideration the standard electromagnetic compatibility (EMC) requirement in order to avoid any legal actions or sanctions that may emanate from the refusal to adhere to strict guidelines. The nature of the strict guidelines as proposed by International Commission on Non-Ionizing Radiation Protection (ICNIRP), are basically limited to two specifications[5]: 1) the body must not be exposed beyond an absolute maximum magnetic field of 27.3 $\mu \mathrm{T}$ and 2) the measured average electromagnetic field strength at the knees, groin, chest and head must be less than $6.25 \mu \mathrm{T}$. Shielding of electromagnetic fields in the design of wireless power transfer system is an essential requirement because of the safety standard specified by the International Commission on Non-Ionizing Radiation Protection (ICNIRP). For most practical applications of WPT systems, there is always a significant amount of leakage flux. The leakage flux is as a result of low magnetic coupling common with most WPT systems. The leakage flux poses a serious problem to the health and wellbeing of the users[6]. As the magnetic coupling factor decreases due to an increase in the airgap, the impact of the external electromagnetic flux linkage poses a lot of danger to humans[6].

A practical approach to minimize the number of electromagnetic flux leakages was to introduce a shielding material at the transmitter and receiver of the WPT systems. Typically, there are two types of magnetic field shielding techniques: one uses magnetic material and the other uses conductive materials[7].The use of magnetic shielding involves the use of magnetic materials. Because of the high permeability of these magnetic materials with respect to air, they tend to concentrate most of the leakage electromagnetic flux into the magnetic material. Two types of magnetic materials are normally used- the metallic oxide/ceramics or metallic ones. The metallic magnetic materials like mumetal and steel are normally used because of their high permeability. Depending on the mode of application, their high magnetic permeability can results in low or high amount of losses at high frequencies, especially in the kilohertz ranges[7]. The use of ceramic materials known as ferrites is another alternative but are mostly not employed because they are better suited for boosting the electromagnetic flux from the transmitter to the receiver[2]. 
The use of conductive materials employs the process of electromagnetic induction in the cancellation of leakage magnetic flux. The induced electric current produced creates an eddy current which opposes the applied magnetic field generating the required shielding effect. For virtually all the

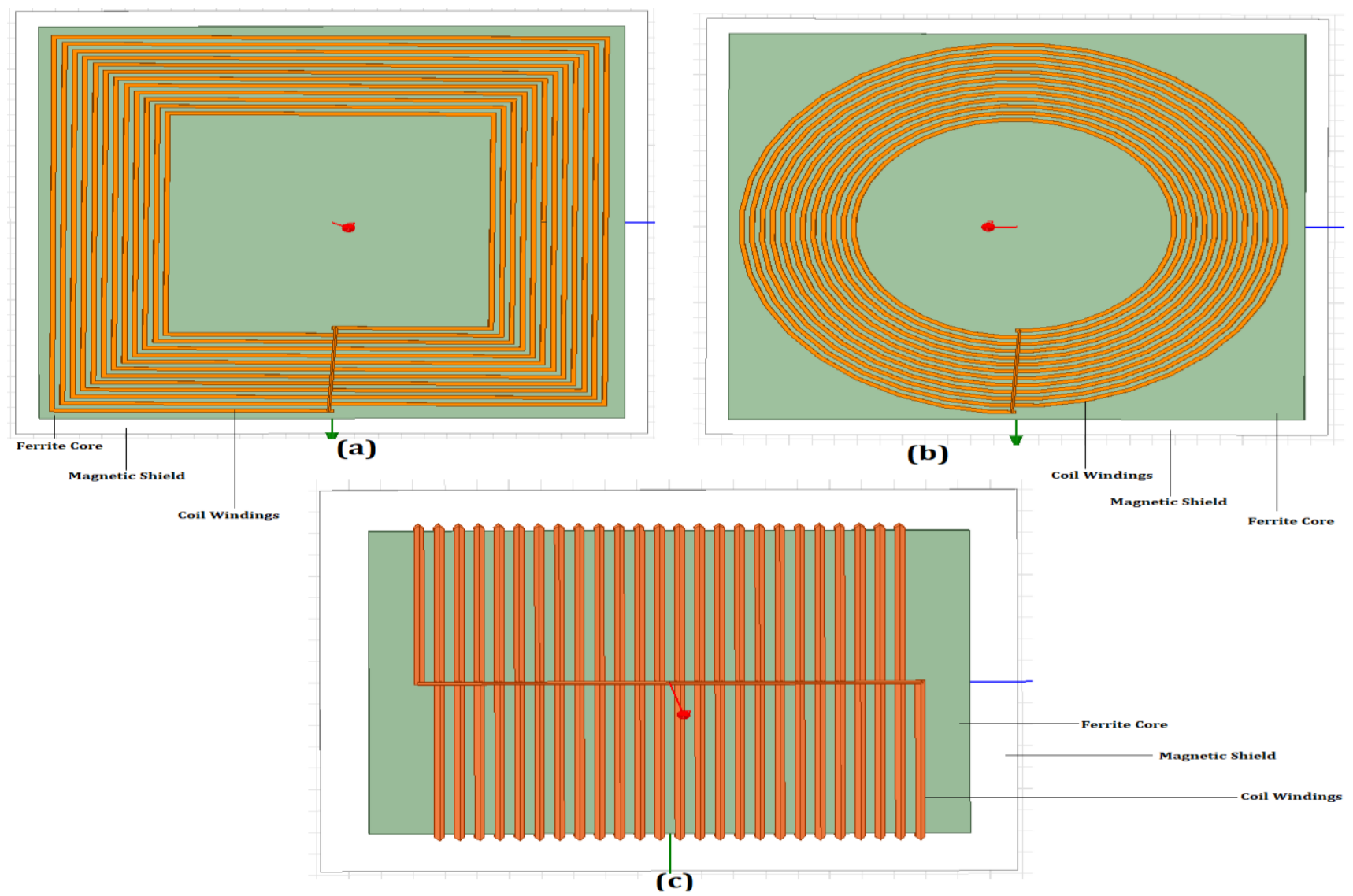

Figure 1. Common Geometries and Shape of Ferrite-Cored Resonant Coil Models. (a) Rectangular Coil (b) Circular Coil. (c) Flux-Pipe Coils

\section{GOVERNING LOSS EQUATIONS}

For most ferrite-cored resonant coil models, there are three types of losses commonly encountered in the WPT system. They are eddy current losses, ohmic losses, and core losses[12]-[14]. research work studied, aluminium was used as the shielding material[7]-[11]. The choice of aluminium is because of its flexibility, conductivity and low weight. But, there are other alternative options which will be analyzed in this paper.

In this paper, a finite element analysis was undertaken on three ferrite-cored resonant coils in order to evaluate the impact of the magnetic and conductive shield on the amount of eddy current losses in the coil system. The conductive materials used in the analyses are aluminium and copper while the magnetic materials selected for analyses are Mumetal and electrical steel. The finite element analysis approach gives a close approximation of the amount of losses expected in a practical setting. The finite element modelling software tools used in this analysis is the Ansys Maxwell 3-D software. The accuracy of the simulation results based on the design environment, physical modelling and boundary condition have been evaluated against published design prototypes of [2], [9] and an error tolerance of $\pm 6 \%$ was reported.
The ohmic losses (W) normally occur in the coil windings is mathematically expressed as[15][16];

$P_{\text {ohmic }}=I^{2} R_{a c}$

Where I is the current in the coil windings measured in amperes (A), $R_{a c}(\Omega)$ is the A.C resistance of the winding coils. The A.C resistance consists of resistance due to the skin and proximity effect[15] as well as the D.C resistance of the coils.

Similarly, the losses (W) in the ferrite core known as the core loss (Pcore) can be mathematically represented as[17]:

$P_{\text {core }}=C_{m} F^{\alpha} B_{\max }^{\beta}$

$c_{m}, \alpha$ and $\beta$ are constants which are dependent on the properties and grade of the core used. In this research, the ferrite core employed is the FDK $6 \mathrm{H} 40$ ferrite core. The values of the constants are given as $C_{m}=2.0312, \alpha=1.418$, 
and $\beta=2.755$ [17]. $\mathrm{F}$ is the operating frequency measured in $\operatorname{Hertz}(\mathrm{Hz})$ and $\mathrm{B}_{\max }$ is the maximum magnetic flux density in the core at a particular excitation current measured in Tesla (T).

According to P. P. Parthasaradhy and S. V Ranganayakulu [12], the eddy current loss per unit mass for a thin sheet of conductive material, due to eddy current under certain conditions of uniform material and magnetic field with no skin and proximity effect is given by;

$P_{e d d y}=\frac{\pi^{2} \cdot B_{\max } \cdot d^{2} \cdot F^{2}}{6 \cdot \rho \cdot D}$

Where $P_{\text {eddy }}$ is the eddy current loss per unit mass $(\mathrm{W} / \mathrm{kg}), \mathrm{d}$ is the thickness of the shielding sheet $(\mathrm{m}), \rho$ is resistivity of the material $(\Omega \mathrm{m})$ and $\mathrm{D}$ is the density of the material $\left(\mathrm{kg} / \mathrm{m}^{3}\right)$.
From the equation given above, it can be noted that using a conductive material with higher resistivity and density reduces the amount of eddy current per unit mass in the shielding plate. Also, an increase in the magnetic flux, sheet thickness and resonant frequency increases the eddy current losses.

\section{FINITE ELEMENT ANALYSIS OF RESONANT COILS}

The finite element analysis in Ansys Maxwell 3-D is undertaken by performing eddy current analysis on the three model coil designs. The physical design specifications is illustrated in Table I and the 3-D model designs are shown in Fig. 2. The finite analysis is done to evaluate the performance of the different coil designs for different shielding topology. The performance indices are ohmic losses, eddy current losses, core losses, self-inductance and coupling coefficient.

TABLE I. PHYSICAL SPECIFICATION PARAMETERS FOR PROPOSED RESONANT COIL DESIGNS

\begin{tabular}{|l|c|c|c|}
\hline \multicolumn{1}{|c|}{ Parameter } & $\begin{array}{c}\text { Circular Coil } \\
\text { Design }\end{array}$ & $\begin{array}{c}\text { Rectangular Coil } \\
\text { Design }\end{array}$ & $\begin{array}{c}\text { Flux-Pipe Coil } \\
\text { Design }\end{array}$ \\
\hline Length of Copper wire Used Lcu(m) & 15.4 & 15.4 & 15.4 \\
\hline Cross-sectional Radius of Coil (d) & $3 \mathrm{~mm}$ & $3 \mathrm{~mm}$ & $3 \mathrm{~mm}$ \\
\hline Airgap Z (mm) & 200 & 200 & 200 \\
\hline X-Length of Coils Dlx (mm) & 500 & 50.00 & 297 \\
\hline Y-Length of Coils Dly (mm) & 500 & 50.00 & 26 \\
\hline Coil Turns N & 12 & 12 & 283 \\
\hline Length of Ferrite Core (mm) & 520 & 520 & 375 \\
\hline Width of Ferrite Core (mm) & 520 & 520 & 357 \\
\hline Length of Shield (mm) & 560 & 560 & 435 \\
\hline Width of Shield (mm) & 560 & 560 & 1.5 \\
\hline Thickness of Shield (mm) & 1.5 & 1.5 & \\
\hline
\end{tabular}

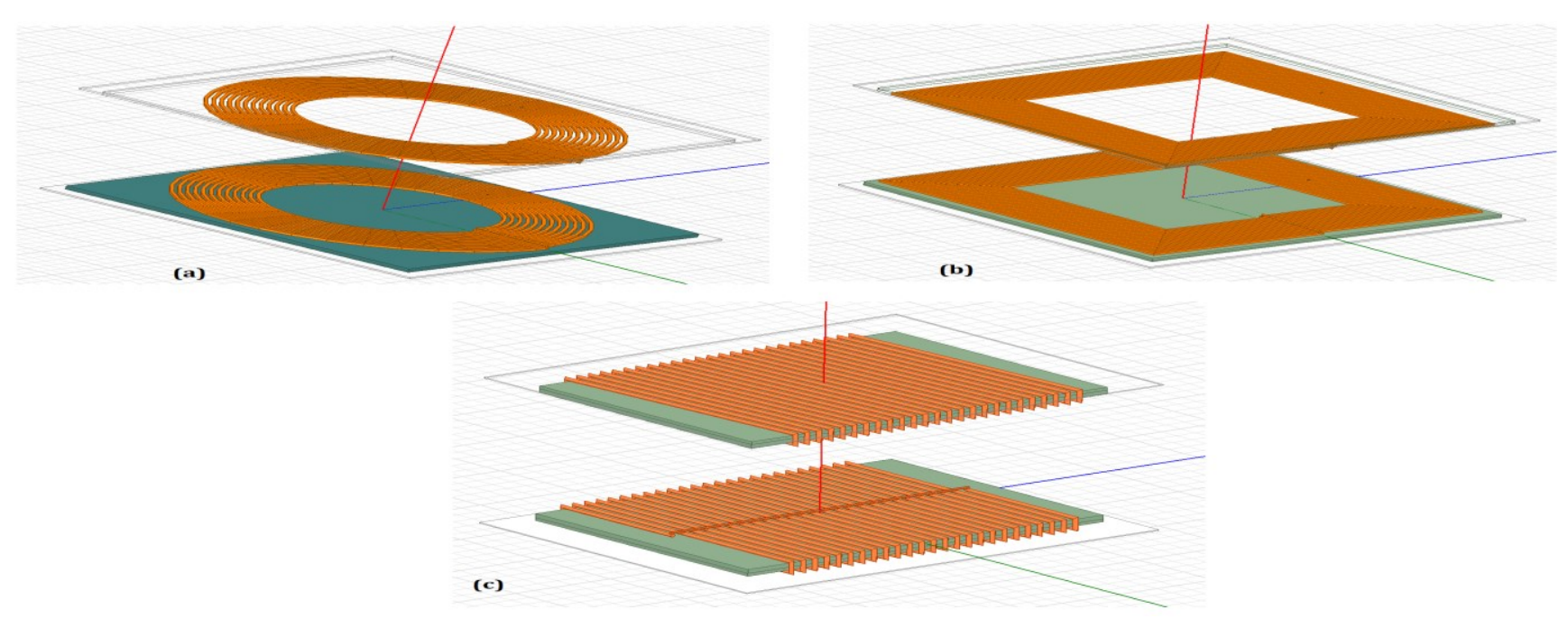

Figure 2. Finite Element Modelling of Resonant Coils using Ansys Maxwell 3-D Software. (a) Circular Resonant Coils (b) Rectangular Resonant Coils. (c) Flux-Pipe Resonant Coils 
TABLE II. PERFORMANCE CHARACTERISTICS OF RESONANT COILS WITH DIFFERENT SHIELD MATERIALS

\begin{tabular}{|c|c|c|c|c|c|c|}
\hline \multirow[b]{2}{*}{ Parameters } & \multicolumn{3}{|c|}{ Aluminum Shield } & \multicolumn{3}{|c|}{ Copper Shield } \\
\hline & $\begin{array}{c}\text { Circular } \\
\text { Coils }\end{array}$ & $\begin{array}{c}\text { Rectangular } \\
\text { Coils }\end{array}$ & $\begin{array}{c}\text { Flux-Pipe } \\
\text { Coils }\end{array}$ & $\begin{array}{c}\text { Circular } \\
\text { Coils }\end{array}$ & $\begin{array}{c}\text { Rectangular } \\
\text { Coils }\end{array}$ & $\begin{array}{c}\text { Flux-Pipe } \\
\text { Coils }\end{array}$ \\
\hline Primary Self-Inductance, $L_{p}$ & $124.98 \mu \mathrm{H}$ & $135.78 \mu \mathrm{H}$ & $211.55 \mu \mathrm{H}$ & $124.98 \mu \mathrm{H}$ & $135.78 \mu \mathrm{H}$ & $211.54 \mu \mathrm{H}$ \\
\hline Secondary Self-Inductance, $L_{s}$ & $124.92 \mu \mathrm{H}$ & $136.03 \mu \mathrm{H}$ & $210.73 \mu \mathrm{H}$ & $124.92 \mu \mathrm{H}$ & $136.02 \mu \mathrm{H}$ & $210.64 \mu \mathrm{H}$ \\
\hline Coupling Coefficient, $k$ & 0.186 & 0.177 & 0.259 & 0.186 & 0.177 & 0.259 \\
\hline Ohmic Losses & $11.57 \mathrm{~W}$ & $11.57 \mathrm{~W}$ & $17.84 \mathrm{~W}$ & $11.58 \mathrm{~W}$ & $13.79 \mathrm{~W}$ & $17.82 \mathrm{~W}$ \\
\hline Core Losses & $13.56 \mathrm{~W}$ & $13.21 \mathrm{~W}$ & $135.21 \mathrm{~W}$ & $13.58 \mathrm{~W}$ & $13.21 \mathrm{~W}$ & $135.14 \mathrm{~W}$ \\
\hline \multirow[t]{3}{*}{ Eddy Current Losses } & $27.20 \mathrm{~W}$ & $45.15 \mathrm{~W}$ & $139.70 \mathrm{~W}$ & $18.08 \mathrm{~W}$ & $29.62 \mathrm{~W}$ & $91.77 \mathrm{~W}$ \\
\hline & \multicolumn{3}{|c|}{ Mumetal Shield } & \multicolumn{3}{|c|}{ Electrical Steel Shield } \\
\hline & $\begin{array}{c}\text { Circular } \\
\text { Coils }\end{array}$ & $\begin{array}{l}\text { Rectangular } \\
\text { Coils }\end{array}$ & $\begin{array}{c}\text { Flux-Pipe } \\
\text { Coils }\end{array}$ & $\begin{array}{l}\text { Circular } \\
\text { Coils }\end{array}$ & $\begin{array}{l}\text { Rectangular } \\
\text { Coils }\end{array}$ & $\begin{array}{c}\text { Flux-Pipe } \\
\text { Coils }\end{array}$ \\
\hline Primary Self-Inductance, $L_{p}$ & $133.43 \mu \mathrm{H}$ & $151.47 \mu \mathrm{H}$ & $425.04 \mu \mathrm{H}$ & $131.72 \mu \mathrm{H}$ & $149.39 \mu \mathrm{H}$ & $603.92 \mu \mathrm{H}$ \\
\hline Secondary Self-Inductance, $L_{s}$ & $133.48 \mu \mathrm{H}$ & $151.67 \mu \mathrm{H}$ & $420.73 \mu \mathrm{H}$ & $131.70 \mu \mathrm{H}$ & $149.472 \mu \mathrm{H}$ & $597.02 \mu \mathrm{H}$ \\
\hline Coupling Coefficient, $k$ & 0.219 & 0.220 & 0.123 & 0.214 & 0.214 & 0.080 \\
\hline Ohmic Losses & $11.58 \mathrm{~W}$ & $13.89 \mathrm{~W}$ & $1527.46 \mathrm{~W}$ & $11.58 \mathrm{~W}$ & $13.81 \mathrm{~W}$ & $652.49 \mathrm{~W}$ \\
\hline Core Losses & $8.15 \mathrm{~W}$ & $6.60 \mathrm{~W}$ & $430.88 \mathrm{~W}$ & $19.05 \mathrm{~W}$ & $22.09 \mathrm{~W}$ & $1178.04 \mathrm{~W}$ \\
\hline Eddy Current Losses & $0.0052 \mathrm{~W}$ & $0.10 \mathrm{~W}$ & $3013.69 \mathrm{~W}$ & $4.19 \mathrm{~W}$ & $6.58 \mathrm{~W}$ & $1638.76 \mathrm{~W}$ \\
\hline
\end{tabular}

At an excitation current of $50 \mathrm{~A}$ and a resonant frequency of $50 \mathrm{kHz}$, an eddy current analysis was performed on the three coil designs with different shielding materials and the results are presented in Table II. For each of the coil designs, the selfinductance, coupling coefficient, ohmic losses and core losses were relatively the same for all cases using the conductive shields of aluminium and copper materials.

With respect to magnetic shields, there is a noticeable impact of the magnetic shield on the self-inductance, coupling coefficient and core losses in the three model coil designs. While the magnetic material increases the self-inductance and coupling factor for the circular and rectangular coils, there is a significant reduction in the amount of core losses and eddy current losses. In contrast, the use of a magnetic shield for the flux-pipe model coils causes a reduction in coupling coefficient while significantly increasing the values of self-
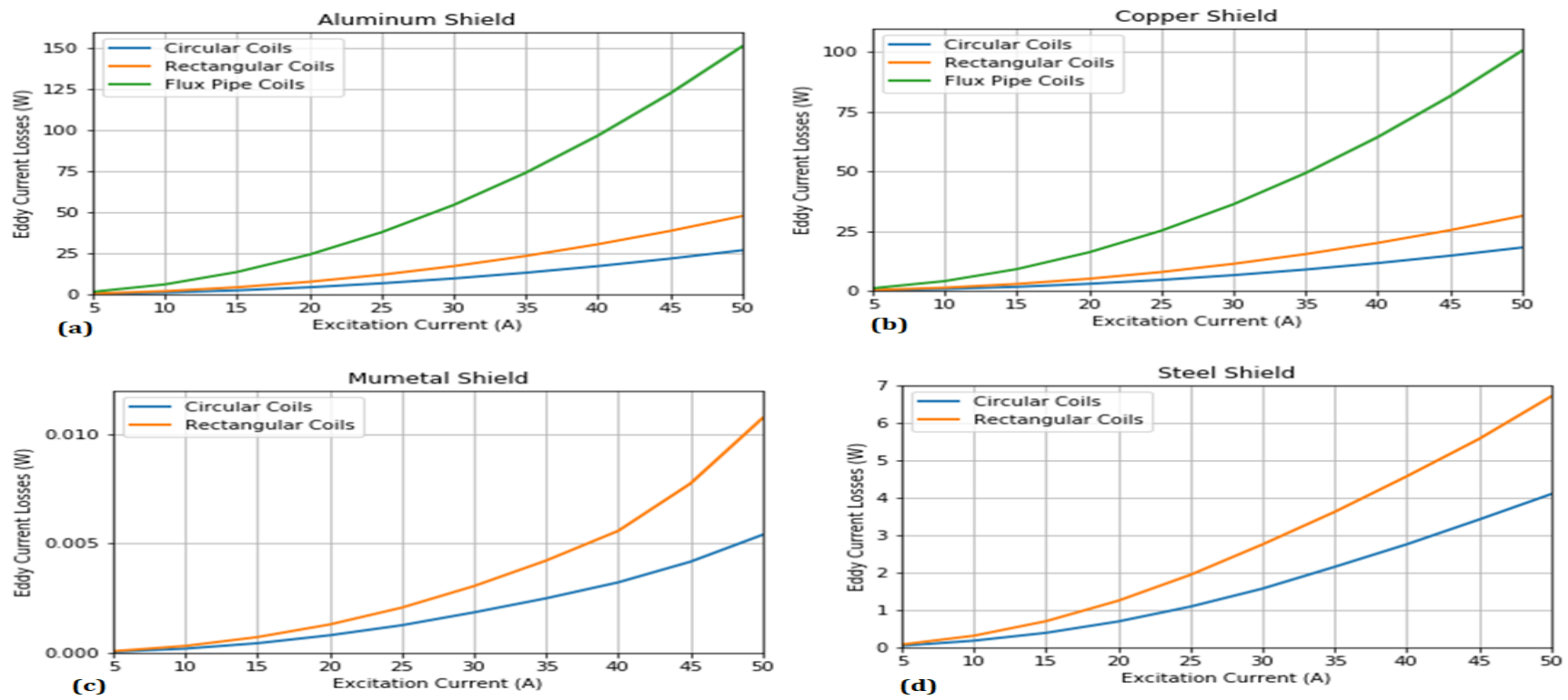

Figure 3. Eddy Current Analysis of Resonant Coils at Constant Frequency using Different Shield Materials 
inductance and the three losses in the system. From the results presented, magnetic shields are poor choice of material for flux-pipe resonant coils as they extremely increase the amount of losses in the system. The unusual behaviour of magnetic shields is as result of their high value of magnetic permeability which creates high core losses and proximity effects on the both the ferrite core and coil windings respectively.

\section{A) Parametric Loss Evaluation at Constant Frequency}

From the results presented in Table I, it is noted that magnetic materials are not suitable for shielding applications for fluxpipe coil systems and is thereby discarded. Further analysis was done by undertaken on the three coil designs by performing a parametric sweep of excitation current of between $5 \mathrm{~A}$ and $50 \mathrm{~A}$ at a fixed resonant frequency of 50 $\mathrm{kHz}$. The result of the analyses are presented in Fig.3. From the result presented, it is observed that the eddy current losses in each coil designs increase with an increase in excitation current; with the flux-pipe coil design having the highest losses. With respect to the circular and rectangular coil designs, the Mumetal shielding topology gives the lowest eddy current losses. This is as a result of Mumetal having higher magnetic permeability than electrical steel. The Mumetal absorbs the leakage magnetic fluxes that emanates from the ferrite core. But for practical purpose, the electrical will be the optimal choice because it is more affordable than Mumetal.
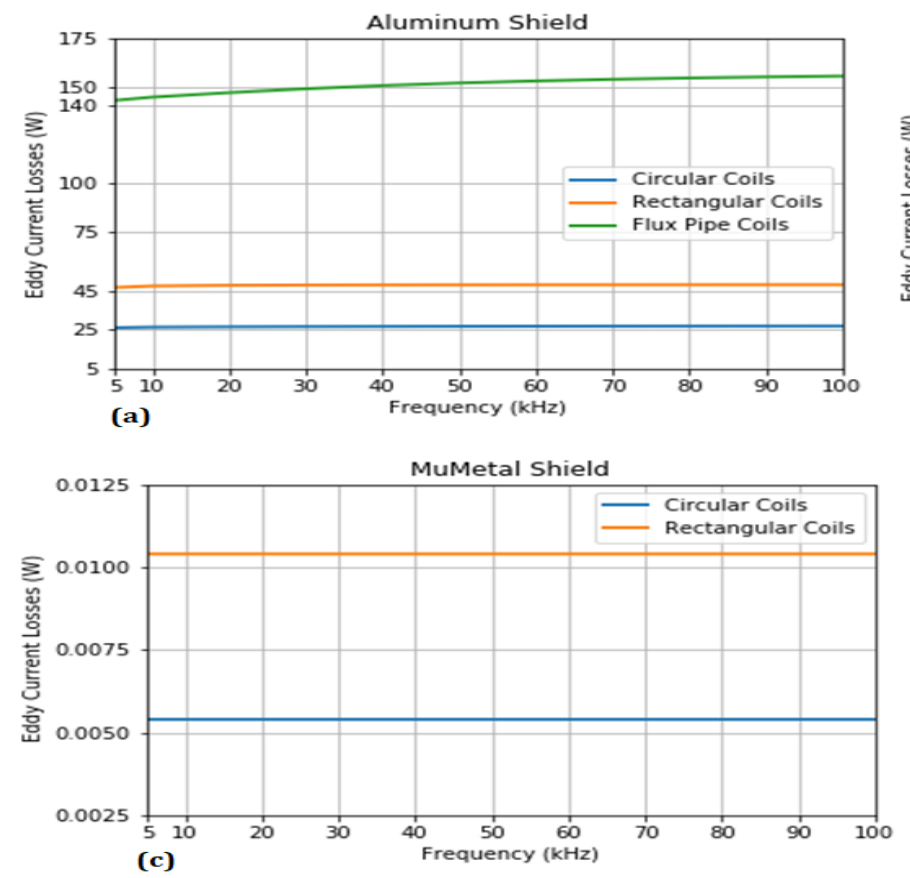

Figure 4. Eddy Current Analysis of Resonant Coils at Constant Excitation Current using Different Shield Materials

\section{B) Parametric Loss Evaluation at Constant Current}

At a fixed excitation current of $50 \mathrm{~A}$, a finite element analysis was performed on the three coils was performed by subjecting each coil model designs to a parametric sweep of resonant frequencies of between $5 \mathrm{kHz}$ and $100 \mathrm{kHz}$ and the value of the eddy current losses in each of the coil system evaluated. The result of the analyses are presented in Fig. 4. From the result shown in Fig. 4, it is observed that an increase in the value of resonant frequencies below $100 \mathrm{kHz}$ has relatively no impact on the amount eddy current losses for both conductive and magnetic shield materials. It is also noticed that for the flux-pipe resonant coil model, the copper shield topology has a relatively less amount of eddy current losses when compared with the amount of eddy current losses present using the aluminium shield topology. For the flux-pipe coil models, the evaluated losses using copper shield topology is less than 100 $\mathrm{W}$ over the range of parametric resonant frequencies, while the use of aluminium shield recorded over $140 \mathrm{~W}$ of eddy current losses over the same range of resonant frequencies. Thus, for practical applications, the use of copper shield will be the most suitable shielding topology for flux-pipe resonant coils.

In contrast, almost zero eddy current losses were observed for the rectangular and circular coil designs when Mumetal was used as the shield material. As already discussed, the lower amount of eddy current losses recorded when compared with electrical steel is as a result of higher magnetic permeability properties of Mumetal. This inherent property of Mumetal creates a low reluctance path for the leakage magnetic fluxes coming out underneath the ferrite core. But for practical application, the electrical steel would be the optimum choice
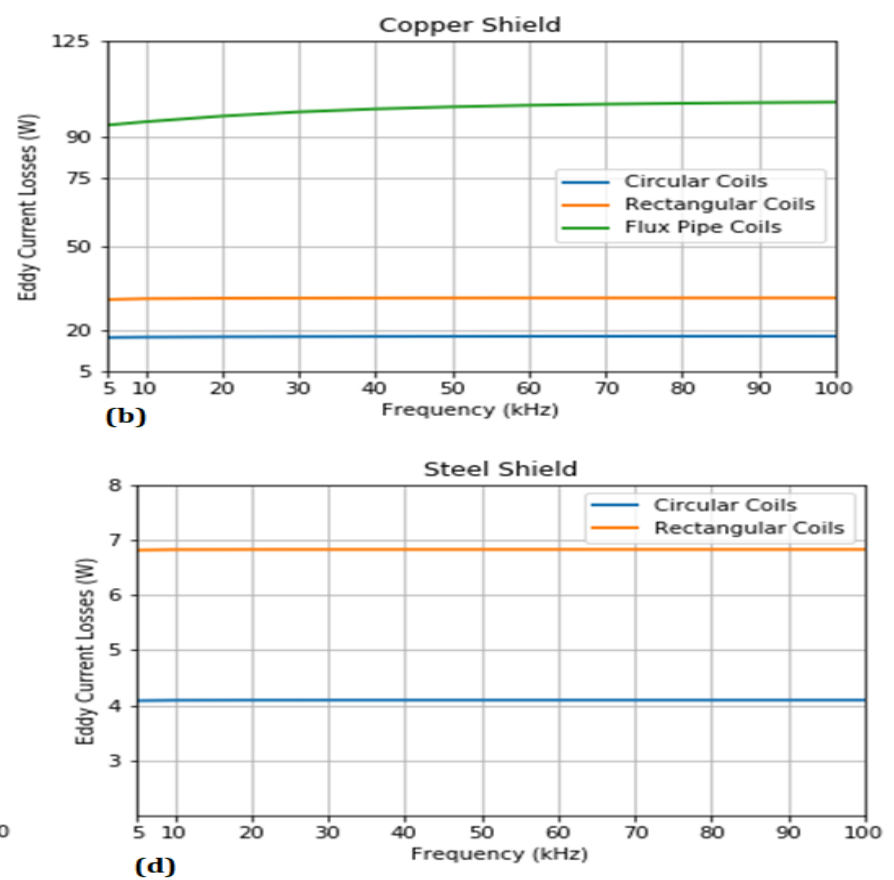

of shield material because it is more affordable. The eddy current losses observed in the system is less than $7 \mathrm{~W}$ for both the circular and rectangular coil designs. 


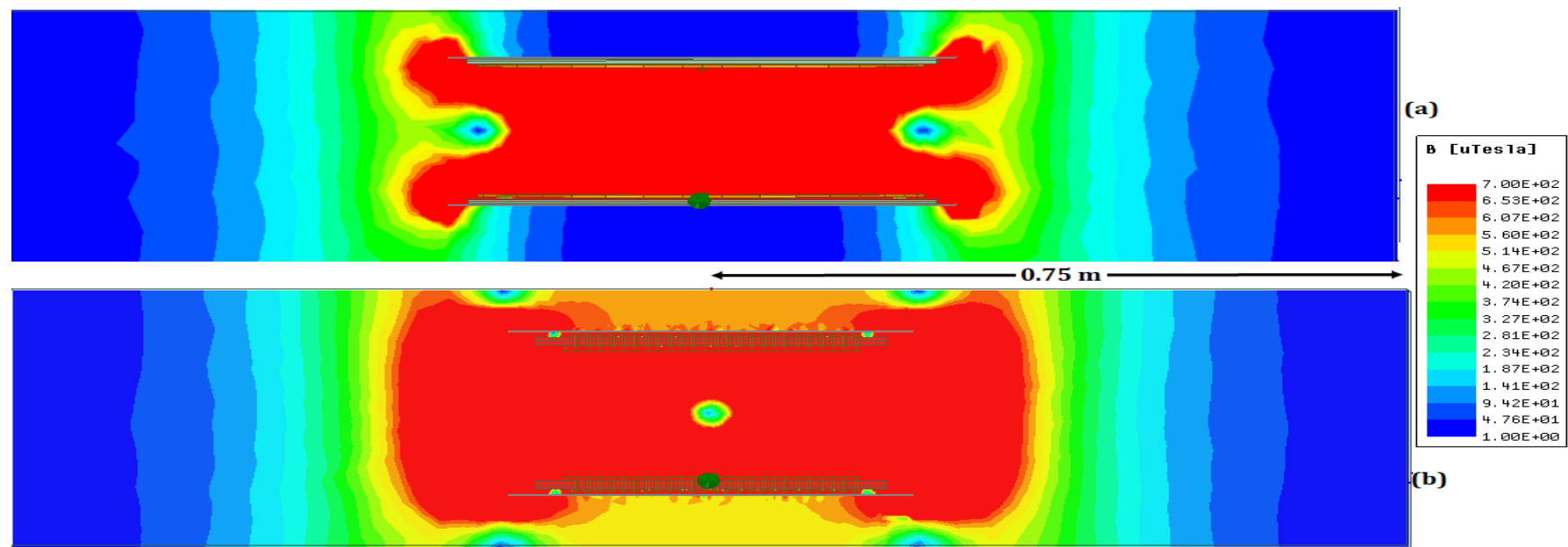

Figure 5. Magnetic Radiation Performance of Resonant Coils using Optimal Shield Materials. (a) Circular Coils. (b) Flux-Pipe coils

\section{C) Evaluation of Radiation Performance}

In order to ensure that the evaluated optimal shield topology conforms to the guidelines proposed by ICNIRP, each of the coil design was subjected to a magnetostatic analysis for an 8 $\mathrm{kW}$ WPT system. The magnetic field distribution for the circular and flux-pipe resonant coils is evaluated and shown in Fig. 5. From the figures shown in Fig. 5, it is noted that the magnetic field radiation falls below the regulation limits 27.3 $\mu \mathrm{T}$ at a distance of $0.75 \mathrm{~m}$ from the centre of each coil models.

\section{CONCLUSION}

This paper presents a loss evaluation of ferrite-cored wireless power transfer (WPT) systems using conductive and magnetic shield material. From the results presented in the analyses, it was noted that ohmic losses and core losses in the system are independent of the type of conductive shield used. In contrast, it was noted that the self-inductance, coupling coefficient and losses in the system is affected by the type of magnetic shield used. For the flux-pipe resonant coil system, high amount of power losses was recorded when used with a magnetic shield materials while a low amount of power losses was recorded in the circular coil and rectangular coil resonant systems when the magnetic materials was used as the shields.

For an optimal WPT system requiring a low amount of power losses, it was established that copper shield is the optimal choice for flux-pipe resonant coils while electrical steel is a more suitable shield material for the circular resonant coil and rectangular resonant coil systems.

\section{REFERENCES}

[1] K. A. Kalwar, M. Aamir, and S. Mekhilef, "Inductively coupled power transfer (ICPT) for electric vehicle charging - A review," Renew. Sustain. Energy Rev., vol. 47, pp. 462-475, 2015.

[2] G. Lempidis, "Wired and wire less charging of electri ic vehicles," pp. 1-7, 2014.

[3] M. Chigira, Y. Nagatsuka, Y. Kaneko, S. Abe, T. Yasuda, and A. Suzuki, "Small-size light-weight transformer with new core structure for contactless electric vehicle power transfer system," IEEE Energy Convers. Congr. Expo. Energy Convers. Innov. a
Clean Energy Futur. ECCE 2011, Proc., pp. 260-266, 2011.

Y. Nagatsuka, N. Ehara, Y. Kaneko, S. Abe, and T. Yasuda, "Compact contactless power transfer system for electric vehicles," 2010 Int. Power Electron. Conf. - ECCE Asia -, IPEC 2010, pp. 807-813, 2010.

[5] H. H. Wu, A. Gilchrist, K. D. Sealy, and D. Bronson, "A high efficiency $5 \mathrm{~kW}$ inductive charger for EVs using dual side control," IEEE Trans. Ind. Informatics, vol. 8, no. 3, pp. 585-595, 2012.

[6] H. Takanashi, Y. Sato, Y. Kaneko, S. Abe, and T. Yasuda, "A large air gap $3 \mathrm{~kW}$ wireless power transfer system for electric vehicles," 2012 IEEE Energy Convers. Congr. Expo. ECCE 2012, pp. 269$274,2012$.

[7] S. Ahn, C. Hwang, and H. H. Park, "Optimized shield design for reduction of EMF from wireless power transfer systems," IEICE Electron. Express, vol. 11, no. 2, pp. 1-9, 2014.

[8] M. Budhia, G. Covic, and J. Boys, "A new IPT magnetic coupler for electric vehicle charging systems," IECON Proc. (Industrial Electron. Conf., pp. 2487-2492, 2010.

[9] K. Throngnumchai, A. Hanamura, Y. Naruse, and K. Takeda, "Design and evaluation of a wireless power transfer system with road embedded transmitter coils for dynamic charging of electric vehicles," World Electr. Veh. J., vol. 6, no. 4, pp. 848-857, 2013.

[10] D. Kürschner, C. Rathge, and U. Jumar, "Design methodology for high efficient inductive power transfer systems with high coil positioning flexibility," IEEE Trans. Ind. Electron., vol. 60, no. 1, pp. 372-381, 2013.

[11] D. K??rschner, C. Rathge, and A. Hoppe, "Design of inductive power transmission systems considering tolerances and power loss," IECON Proc. (Industrial Electron. Conf., pp. 378-383, 2009.

[12] P. P. Parthasaradhy and S. V Ranganayakulu, "Hysteresis and eddy current losses of magnetic material by Epstein frame method-novel approach," Int. Conf. Innov. Electr. Electron. Eng., pp. 85-93, 2014.

[13] D. Chen, L. Wang, C. Liao, and Y. Guo, "The power loss analysis for resonant wireless power transfer," IEEE Transp. Electrif. Conf. Expo, ITEC Asia-Pacific 2014 - Conf. Proc., pp. 1-4, 2014.

[14] D. Barth, B. Klaus, and T. Leibfried, "Litz wire design for wireless power transfer in electric vehicles," in WPTC 2017 - Wireless Power Transfer Conference, 2017.

[15] S. Sotiriou, "Analysis of Operation and System Losses of an Inductive Power Transfer System for Wireless Charging of Electric Vehicles," no. September, 2014.

[16] K. Jaber, B. Ben Saleh, A. Fakhfakh, and R. Neji, "Modeling and simulation of electrical vehicle in VHDL-AMS," 2009 16th IEEE Int. Conf. Electron. Circuits Syst. ICECS 2009, pp. 908-911, 2009.

[17] M. Mohammad, S. Kwak, and S. Choi, "Core design for better misalignment tolerance and higher range of wireless charging for HEV," Conf. Proc. - IEEE Appl. Power Electron. Conf. Expo. APEC, vol. 2016-May, no. 2, pp. 1748-1755, 2016. 